\title{
Correction to: Practical Aspects in the Application of Geometrical Product Specifications and Verification (GPS) in the Micro and Nano-Scale Manufacturing
}

N. M. Durakbasa and G. Poszvek

Correction to:

Chapter "Practical Aspects in the Application of Geometrical Product Specifications and Verification (GPS) in the Micro and Nano-Scale Manufacturing" in: V. D. Majstorovic and N. Durakbasa (Eds.): Proceedings of the 12th International Conference on Measurement and Quality Control - Cyber Physical Issue, LNME, https://doi.org/10.1007/978-3-030-18177-2_21

In the original version of this chapter, the authors had reproduced five verbatim excerpts from References [5], [7] and [9]. Though these references were properly mentioned in chapter-end references' list, they were reproduced without quotation marks and without proper citations.

Now, the chapter has been updated with proper acknowledgement of the missing citations. 